20

\title{
Определение коэффициента диффузии растворов метиленового синего в дентине зуба человека с помощью спектроскопии отражения и их антибактериальная активность при лазерном воздействии*
}

\author{
(C) А.А. Селифонов ${ }^{1,2}$, О.Г. Шаповал ${ }^{2}$, А.Н. Микеров ${ }^{2}$, В.В. Тучин ${ }^{1,3,4,5}$ \\ ${ }^{1}$ Саратовский национальный исследовательский государственный университет им. Н.Г. Чернышевского, \\ 410012 Саратов, Россия \\ ${ }^{2}$ Саратовский государственный медицинский университет им. В.И. Разумовского, \\ 410012 Саратов, Россия \\ ${ }^{3}$ Национальный исследовательский томский государственный университет, \\ 634050 Томск, Россия \\ ${ }^{4}$ Университет ИТМО, \\ 197101 Санкт-Петербург, Россия \\ ${ }^{5}$ Институт проблем точной механики и управления РАН, \\ 410028 Саратов, Россия \\ e-mail: selif-ei@yandex.ru
}

Поступила в редакцию 15.12.2018 г.

В окончательной редакции 22.02.2019 г.

Принята к публикации 26.02.2019 г.

\begin{abstract}
Работа посвящена определению коэффициентов диффузии метиленового синего в водном растворе и в мицеллярном растворе катионного поверхностно-активного вещества в срезах дентина зуба человека in vitro с помощью метода оптической спектроскопии диффузного отражения, используя модель свободной диффузии. Было определено, что коэффициент диффузии в среднем составляет для водного раствора метиленового синего $(6.74 \pm 1.32) \cdot 10^{-6} \mathrm{~cm}^{2} / \mathrm{s}$ и $(1.93 \pm 0.24) \cdot 10^{-6} \mathrm{~cm}^{2} / \mathrm{s}$ для мицеллярного раствора красителя. Проведены исследования токсичности при дневном свете в отсутствие лазерного излучения растворов метиленового синего в воде и в растворе цетилпиридиния хлорида, а также фотодинамического действия лазерного излучения $(662 \mathrm{~nm})$ на клетки штаммов Candida albicans, Staphylococcus aureus FDA $209 P$ и Lactobacillus. Показано, что фотодинамическое действие лазерного излучения имеет выраженный подавляющий эффект на все исследуемые штаммы микроорганизмов.
\end{abstract}

DOI: $10.21883 /$ OS.2019.06.47779.59-19

\section{Введение}

Диффузия химических агентов в биологических тканях, в том числе в тканях зуба, протекает на всех этапах метаболических процессов жизнедеятельности организма. В частности, диффузия воды и зубного ликвора является необходимым процессом для функционирования живого зуба, который влияет на его твердость [1]. С помощью диффузии просветляющих агентов по методу оптического просветления [2-4] возможно увеличение глубины проникновения лазерного излучения в биоткань, что представляет интерес как для диагностики, так и для терапии.

Исследование проницаемости тканей зуба человека по отношению к различным химическим агентам представляет также интерес в связи с широким кругом

\footnotetext{
* The 22nd Annual Conference Saratov Fall Meeting 2018 (SFM'18): VI International Symposium, „Optics and Biophotonics“ and XXII International School for Junior Scientists and Students on Optics, Laser Physics \& Biophotonics, September 24-29, 2018, Saratov, Russia. https://www.sgu.ru/structure/fiz/saratov-fall-meeting/previousconferences/saratov-fall-meeting-2018
}

проблем, связанных с лечением зубов и уходом за ними. Диффузия в дентине широко применяемых в клинической практике агентов для отбеливания изучалась в связи с обнаружением цитотоксичности этих агентов [5]. Проникновение агентов при определении силы адгезии различных материалов, применяемых для создания и покрытия костных имплантатов, а также при изменении адгезии различных видов бактерий на поверхности зуба и в корневых каналах, что является одной из причин возникновения кариеса, изучалось в работах [6,7]. Методом флуоресцентной микроскопии была проанализирована проницаемость бактерий, в частности Streptococcus mutans, Fusobacterium nucleatum и Porphyromonas gingivalis, в дентине in vitro $[8,9]$. Авторы работы [10] изучали диффузию при устранении окраски дентина после эндодонтического лечения корневого канала зуба метиленовым синим (МС или МВ в английской транскрипции).

Одним из перспективных активно развивающихся направлений в современной стоматологии является метод антимикробной фотодинамической терапии, осно- 
ванный на использовании деструктивного эффекта энергии фотохимических реакций. Антимикробная фототерапия - принципиально новый метод воздействия на воспалительный процесс, не имеющий ничего общего с механизмом действия антибиотиков или антисептиков. В этой связи для создания эффективных протоколов лечения в помощь врачам-клиницистам принципиально важным является рассмотрение вопроса диффузии фотосенсибилизирующего агента в ткань дентина. МВ давно известен как недорогой, доступный, практически не токсичный и не проникающий в системный кровоток при местном применении препарат, который обладает антимикробными и фотосенсибилизирующими свойствами. МВ давно и успешно применяется в стоматологии для диагностики участков деминерализации зубов, при определении стоматологических индексов гигиены, лечения стоматита, кариеса, язвенного гингивита, герпеса в полости рта, а также для ускорения регенерации слизистой и подавления патогенов в твердых и мягких тканях пародонта $[11,12]$. МВ - основной тиазиновый краситель, имеет структурную формулу<smiles></smiles>

Активным действующим веществом препарата является хлорид метилтиониния. Механизм действия этого препарата основан на его способности образовывать малорастворимые комплексные соединения с мукополисахаридами и белками бактериальной клетки, что приводит к гибели микроорганизмов и определяет его темновую токсичность. В отличие от цетилпиридиния хлорида (ЦПХ или СРС, cetylpyridinium chloride) МВ обладает фотосенсибилизирующими свойствами, молекулы которого под действием видимого света (с центральной длиной волны $668 \mathrm{~nm}$ ) способны переходить в возбужденное (триплетное) состояние, а при возврате в основное - передавать полученную энергию растворенному в ткани кислороду, который переходит в чрезвычайно химически активное синглетное состояние. Взаимодействуя с белками, липидами, липопротеидами и другими макромолекулами, синглетный кислород запускает каскад свободнорадикальных реакций, в результате которых повреждаются опухолевые клетки, микроорганизмы, другие патологические биологические структуры. Фотосенсибилизатор способен избирательно накапливаться в энергодефицитных клетках (опухолевых, микробных, поврежденных), что обусловливает возможность селективного использования фотодинамической реакции для их уничтожения. В роли акцептора энергии выступает кислород, который всегда присутствует в биологических тканях. Необходимость поисков новых эффективных и безопасных методик антимикробного воздействия при лечении стоматологических заболеваний стала причиной широкого изучения усиленной антимикробной активности МВ в экспериментах in vitro и in vivo при его активации светом [13-15]. Авторы [16] доказали эффективность проведения фотодинамической терапии с использованием $0.1 \%$ водного раствора МВ в сочетании с $\mathrm{He}-\mathrm{Ne}$-лазерным излучением $(632.8 \mathrm{~nm})$ на Staphylococcus aureus при экспериментах in vitro и для лечения слизистой оболочки верхнечелюстной пазухи больных с острым и хроническим верхнечелюстным синуситом по сравнению с консервативными методами лечения заболевания в экспериментах in vivo. В работе [17] была выявлена эффективность использования зубной щетки, излучающей красный свет (R-LETB, $663 \mathrm{~nm}$ ), в комбинации с $0.1 \%$ раствором МВ в течение 3 min (при воздействии на Micrococcus, Stomatococcus, and Staphylococcus lugdensis in vitro) и для уменьшения зубного налета и лечения гингивита, что объясняется многофакторным терапевтическим действием данного лечения на патологию полости рта.

Несмотря на значительное число публикаций, в которых изучается диффузия агентов в биологических тканях, количественная оценка этого процесса приводится далеко не всегда. Нами был рассчитан коэффициент диффузии МВ в дентине зуба человека in vitro в водном растворе и в растворе $0.05 \%$ СРС.

СРС - катионное поверхностно-активное вещество ПАВ (surfactant) общей формулы $\left[\mathrm{C}_{16} \mathrm{H}_{33} \mathrm{NC}_{5} \mathrm{H}_{5}\right]^{+} \mathrm{Cl}^{-}$, критическая концентрация мицеллообразования (ККМ или СCM, critical concentration of micelle) которого составляет $0.045 \%$. Является универсальным антисептическим средством, имеет следующую структурную формулу:

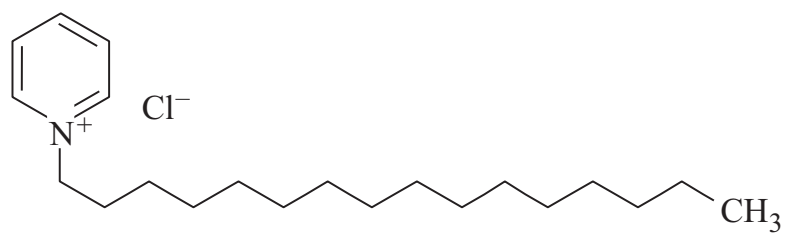

Он эффективен в отношении грамположительных и грамотрицательных бактерий, а также некоторых вирусов и грибов. Благодаря значительной увлажняющей способности и незначительному поверхностному натяжению СРС хорошо проникает в глубокие слои слизистой оболочки, где оказывает бактерицидное действие. СРС - антибактериальное средство против инфекции ротовой полости, широко применяемое в составе антисептических жидкостей для полоскания рта, зубных паст, пастилок и леденцов при заболеваниях в ларингооторинологии.

В настоящей работе была поставлена задача определения эффективного коэффициента диффузии водного раствора МВ $(0.001 \%)$ и МВ в растворе ЦПХ (СРС) $(0.001 \%)$ в дентине зуба человека с помощью метода оптической спектроскопии диффузного отражения, используя модель свободной диффузии. Также проведены 
исследования по изучению антибактериальной активности МВ в водном растворе, в растворе СРС, а также комбинированного действия этих растворов с лазерным излучением (662 nm) на клетки штаммов Candida albicans, Staphylococcus aureus FDA 209P и Lactobacillus.

\section{Материалы и методы}

\section{Материалы для исследования}

Материалом для in vitro исследования послужили удаленные зубы человека (моляры). Зубы были извлечены у пациентов в стоматологической клинике по ортодонтическим показаниям, возраст пациентов составил от 15 до 25 лет. Удаленные зубы хранились в физиологическом растворе при $4^{\circ} \mathrm{C}$ в темном месте. Влажные зубы разрезались алмазным диском на срезы толщиной около $1 \mathrm{~mm}$ вдоль оси роста. Срезы протравливали 35\% ортофосфорной кислотой в течение $15 \mathrm{~s}$, далее удаляли кислоту с помощью струи воды. Затем с помощью щетки и 95\% этилового спирта проводили очистку поверхности от продуктов распиливания и других внешних загрязнителей, для этого спил (образец) помещали в ультразвуковую ванну Techsonic UD100 SH-45 L на 10 min и протирали его безворсовой салфеткой, смоченной в спирте. Высушивали образцы на воздухе в течение суток. Толщина спилов (образцов) биоткани измерялась микрометром, измерения проводились в нескольких точках образца и усреднялись. Точность каждого измерения $\pm 10 \mu \mathrm{m}$. Всего в эксперименте исследовалось шесть спилов (образцов) различных зубов: для диффузии - три спила (образца) и для определения микроэлементного состава дентина - три спила (образца).

Для измерения коэффициентов отражения в оптическом диапазоне использовался двухлучевой спектрофотометр Shimadzu UV-2550(РC) (Япония) с интегрирующей сферой в режиме диффузного отражения в спектральном диапазоне 200-800 nm. Источником излучения служила галогеновая лампа с фильтрацией излучения в исследуемом спектральном диапазоне. Нормировка спектров перед началом измерений проводилась на сигнал от эталонного отражателя $\mathrm{BaSO}_{4}$. Все эксперименты проводились при комнатной температуре $\left(\sim 25^{\circ} \mathrm{C}\right)$ и нормальном атмосферном давлении. На рис. 1 указано расположение образца при регистрации спектров диффузного отражения.

Для измерения коэффициентов поглощения растворов МВ в воде и в мицеллярном растворе СРС использовали спектрофотометр Shimadzu UV-2550(РC) (Япония) без интегрирующей сферы в режиме поглощения. Растворы помещались в кварцевые кюветы (шириной $1 \mathrm{~cm})$, в качестве раствора сравнения использовалась дистиллированная вода. Все эксперименты проводились при комнатной температуре $\left(\sim 25^{\circ} \mathrm{C}\right)$ и нормальном атмосферном давлении.

Для облучения суспензий бактериальных клеток, окрашенных раствором МВ, использовали лазерное из- лучение, источником которого служил диодный лазер на основе AlGaInP с максимумом спектра излучения на длине волны $662 \pm 0.2 \mathrm{~nm}$ и шириной полосы на уровне 0.5 , равной $0.8 \mathrm{~nm}$, измеренных на спектрофотометре Ocean Optics HR 4000 CG-UV-NIR (CШA). Экспериментальная установка обеспечивала плотность мощности излучения на выходе $50 \mathrm{~mW} / \mathrm{cm}^{2}$, которая рассчитывалась на основе измерений падающей мощности на образец с помощью измерителя оптической мощности Gentec- $\varepsilon$, MAESTRO UP 12E-10S-H5DO и размера пучка лазера.

Измерение $\mathrm{pH}$ растворов МВ проводили с помощью $\mathrm{pH}$-метра (EL2-Kit производства фирмы „MettlesToledo“, Швейцария).

В качестве проникающего агента использовался МВ марки ч.д.а. (чистый для анализов, Россия), растворенный в дистиллированной воде и в $0.05 \mathrm{M}$ растворе СРС марки ч.д.а. (КНР). Определение коэффициента диффузии МВ в биоткани было основано на измерении временной кинетики изменения спектра диффузного отражения (СДО или SDR, spectrum of diffuse reflectance). Для проведения этих измерений каждый образец среза зуба фиксировался в специальном зажиме в виде рамки с окном $1 \times 1 \mathrm{~cm}$, погруженной в кювету с водным раствором МВ с концентрацией $0.001 \%$ в соответствующем растворителе. Измерения коэффициента диффузного отражения дентина проводили в течение $2-5 \mathrm{~h}$.

\section{Исследование морфологии и элементного состава дентина зуба человека}

Морфология поверхности срезов зубной ткани исследовалась на сканирующем электронном микроскопе (СЭМ или SEM) Tescan Mira II LMU (Чехия) в режиме детектирования вторичных электронов (при ускоряющем напряжении $30 \mathrm{kV}$ ). Для этого образцы фиксировались на специальной углеродной подложке (углеродный скотч), и на их поверхность напылялось золото. По полученным на SEM-фотографиям оценивали степень очистки образцов от продуктов распиливания. Элементный состав образцов зуба человека определяли на сканирующем электронном микроскопе (в \%) и на рентгенофлуориметре Innov X-5000 (Olympus, США) с кремниевым дрейф-детектором (в единицах ppm). Модельную деминерализацию спилов (образцов) зуба человека проводили в $40 \% \mathrm{HCl}$ (ч. Д. а) в течение $20 \mathrm{~min}$. Для отмывания красителя спилы (образцы) помещали в емкость со $100 \mathrm{ml}$ дистиллированной воды на 24-30 h. Степень очистки образцов проверяли по спектру диффузного отражения, который совпадал с первоначально измеренным для этого образца.

\section{Определение коэффициента диффузии}

Процесс транспорта МВ в срезе дентина зуба человека можно описать в рамках модели свободной диффузии [18]. Геометрически образец твердой ткани 


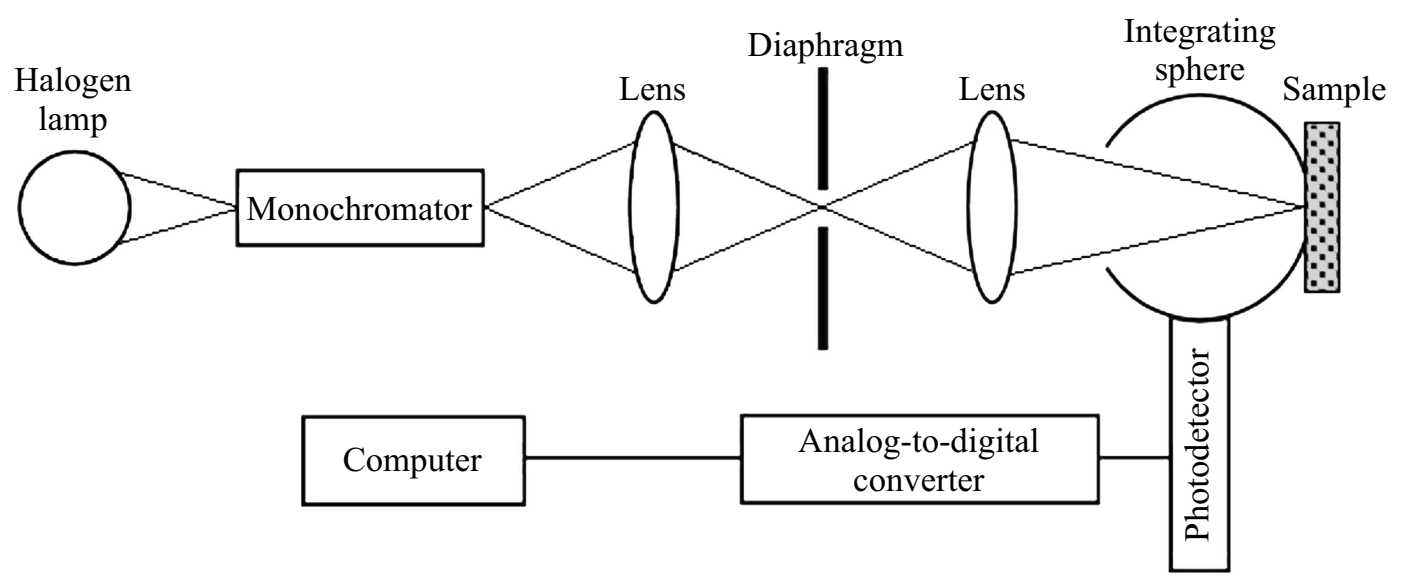

Рис. 1. Схема расположения образца при измерении спектров диффузного отражения с использованием интегрирующей сферы.

дентина является плоско-параллельной пластиной конечной толщины. Дентинные канальца (тубулы) с диаметром $3.0 \pm 1.8 \mu \mathrm{m}$ окружает перитубулярный дентин (более плотный и однородный), между ними находится интертубулярный дентин, более рыхлый и неоднородный [1-4]. Плотность дентинных канальцев достаточно большая (рис. 2), поэтому можно ожидать, что их вклад в общую диффузию будет значительным. Поскольку любая математическая модель является приближенной, необходимо принимать ограничения, соответствующие данной модели. В данном случае вводятся некоторые допущения относительно процесса переноса: 1) имеет место только концентрационная диффузия, т.е. поток красителя в срезе дентина в данной точке пропорционален градиенту концентрации красителя в этой точке, 2) коэффициент диффузии постоянен во всех точках внутри исследуемого образца ткани, 3) диффузия МВ происходит только с одной стороны образца, и объем раствора МВ значительно превышает объем образца зуба, 4) до начала эксперимента предполагается отсутствие красителя во всех внутренних точках образца среза дентина $[19,20]$.

Поскольку при проведении экспериментов проникновение красителя осуществляется только с одной стороны образца, то можно применить второй закон Фика для решения одномерной задачи диффузии, т. е. уравнение

$$
\frac{\partial C(x, t)}{\partial t}=D \frac{\partial^{2} C(x, t)}{\partial x^{2}},
$$

где $C(x, t)$ - концентрация красителя МВ в образце дентина, в $\mathrm{g} / \mathrm{ml} ; D-$ коэффициент диффузии, в $\mathrm{cm}^{2} / \mathrm{s}$; $t$ - время, в течение которого происходит процесс диффузии, в s; $x$ - пространственная координата по толщине образца биоткани $(l)$ в $\mathrm{cm}$. Проводя преобразования, основанные на использовании модифицированного закона Бугера-Ламберта-Бера, подробно описанного в [21,22], получаем конечное выражение

$$
\begin{aligned}
\Delta A(t, \lambda) & =A(t, \lambda)-A(t=0, \lambda)=\Delta \mu_{\mathrm{a}}(t, \lambda) L \\
& =\varepsilon(\lambda) C_{0}\left(1-\exp \left(-\frac{t \pi D}{l^{2}}\right)\right) L,
\end{aligned}
$$

где $\Delta A(t, \lambda)$ - разность между эффективной оптической плотностью $A(t, \lambda)$ в определенный момент времени и $A(t=0, \lambda)$ в начальный момент времени; $\lambda$ - длина волны, в $\mathrm{nm} ; \Delta \mu_{\mathrm{a}}(t, \lambda)$ - разность между коэффициентами поглощения биоткани в определенный момент времени и начальный момент времени, в $1 / \mathrm{cm} ; L-$ средняя длина пробега фотонов; $\varepsilon(\lambda)-$ молярный коэффициент поглощения красителя, в $1 /(\mathrm{cm} \cdot \mathrm{M})$.

Коэффициент диффузии $(D)$ рассчитывался по уравнению (2), учитывая коэффициенты, полученные после аппроксимации экспериментальных данных по методу наименьших квадратов.

\section{Микробиологические исследования}

В качестве объекта исследования использовали стандартные штаммы Staphylococcus aureus FDA 209P, клинически выделенные штаммы Candida albicans и Lactobacillus, полученные разведением препарата „лактонорм“ (Россия). Для выделения и субкультивирования использовали мясо-пептонный агар. Раствор 0.001\% МВ готовили на стерильном физиологическом растворе. Для облучения культур использовали лазерное излучение на длине волны $662 \pm 0.2 \mathrm{~nm}$ с плотностью мощности $50 \mathrm{~mW} / \mathrm{cm}^{2}$ и временем облучения $10 \mathrm{~min}$.

При облучении использовали следующие опытные варианты: контроль (культуру микроорганизмов в концентрации $2 \cdot 10^{3} \mathrm{KOE} / \mathrm{M}$ ( $\mathrm{CFU} / \mathrm{ml}$, colony-forming unit) (колонии образующие единицы), приготовленную по стандарту мутности 10 ед. ФГУН ГИСК им. Л.А. Тарасевича, в физиологическом растворе), а также суспензии микроорганизмов в той же концентрации:

- с добавлением раствора $0.001 \%$ МВ в воде; 


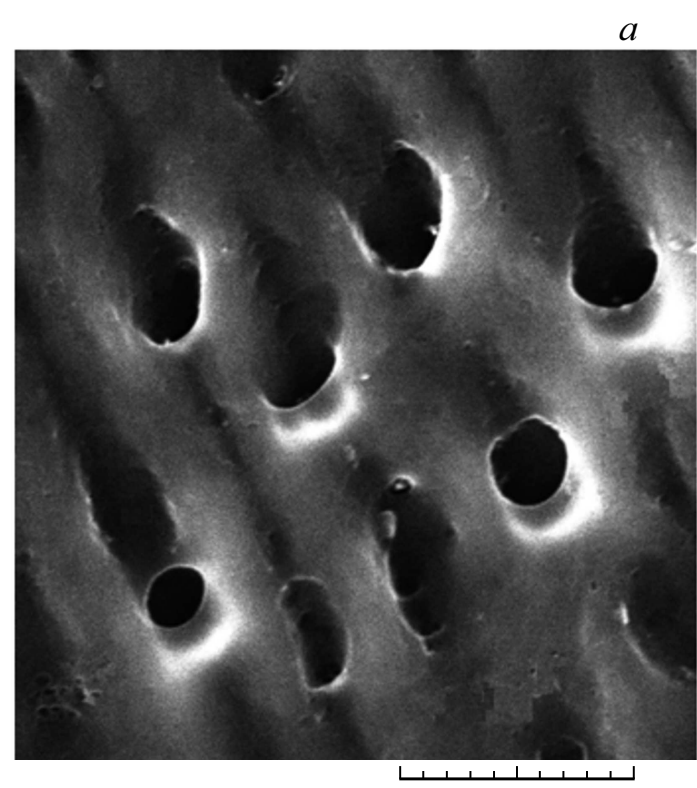

$10 \mu \mathrm{m}$

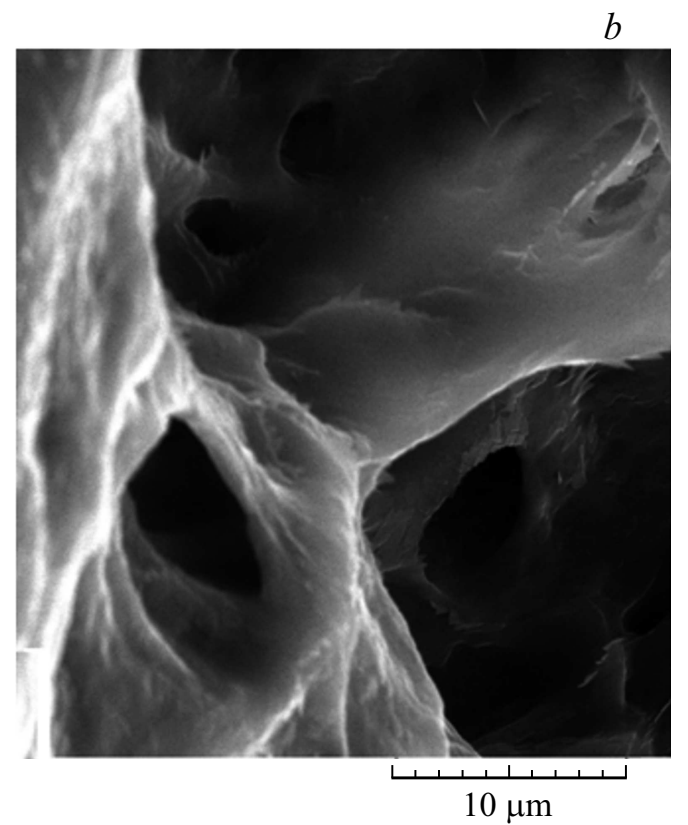

Рис. 2. Электронные микрофотографии (SEM) продольного спила (образца) зуба человека (увеличение в 10000 раз) (SEM MAG: $10.00 \mathrm{kx}$ ): $a$ - часть спила у коронки (середина), $b$ - часть спила у корня.

- с добавлением раствора $0.001 \%$ МВ в мицеллярном растворе СРC;

- с облучением лазерным излучением;

- с облучением лазерным излучением в сочетании с добавлением раствора $0.001 \%$ МВ в воде;

- с облучением лазерным излучением в сочетании с добавлением раствора $0.001 \%$ МВ в мицеллярном растворе СРC.

Культуры исследуемых штаммов микроорганизмов, полученные после разведения приготовленной по стандарту суспензии, имели концентрацию $2 \times 10^{3} \mathrm{CFU} / \mathrm{ml}$. Из этого раствора брали $0.2 \mathrm{ml}$, помещали в малые чашки Петри, добавляли $2 \mathrm{ml}$ раствора $\mathrm{MB}$ различных концентраций, затем непрерывно облучали лазерным излучением в течение $10 \mathrm{~min}$. Затем осуществляли высев $0.5 \mathrm{ml}$ на питательный агар и проводили подсчет выросших колоний, рассчитывая количество CFU в $1 \mathrm{ml}$ облучаемой суспензии после инкубирования в термостате при $37^{\circ} \mathrm{C}$ в течение $24 \mathrm{~h}$. Все посевы повторяли трижды.

\section{Результаты и обсуждения}

\section{Исследования диффузии МВ}

Зуб человека состоит из корня, шейки и коронки, покрытой эмалью - самой твердой тканью зуба. Дентин составляет основную массу зуба, имеет светло-желтую окраску, обладает некоторой эластичностью; он прочнее кости и цемента, но в 4-5 раз мягче эмали. Он состоит из межклеточного вещества, пронизанного дентинными канальцами (тубулами), обусловливающими его трофи- ку. Они имеют внутренний диаметр от 0.5 до $4 \mu \mathrm{m}$ в зависимости от области зуба. Среднее количество дентинных канальцев на единицу объема (плотность) в средней части дентина корня зуба значительно ниже, чем в средней части дентина коронки зуба. Плотность канальцев в дентине, расположенного ближе к внешней части зуба, также значительно отличается от плотности, расположенной вблизи окклюзионной трещины. Замечено, что при низкой плотности дентинных канальцев они имеют более разветвленную структуру. Размер ветвей дентинных канальцев различается в зависимости от расположения: ветви дентинных канальцев, расположенных по периферии, имеют диаметр 0.5-1 $\mu$; мелкие ветви диаметром от 300 до $700 \mathrm{~nm}$ расположены под углом в $45^{\circ}$ и обильны в таких областях, как корень, где плотность канальцев относительно низкая; самые мелкие разветвления диаметром 25-200 nm, они вытянуты под прямым углом от канальцев во всех частях дентина [23]. Авторы делают выводы о необходимости характеристики структуры дентина и плотности дентинных канальцев для испытаний на адгезию различных материалов и в исследованиях проницаемости. Можно считать, что зуб представляет собой пучки согласованных природных световодов. Извитая форма световодов определяет высокую эффективность освещения пульпы практически независимо от того, каким образом свет попадает на внешнюю поверхность зуба. Волноводный эффект существенно более выражен в дентине, чем в эмали $[24,25]$. Выявлена связь различных изменений структуры дентина с наличием таких патологий как остеопороз, кариес, гиперчувствительность зубов и т. д. [26,27]. 

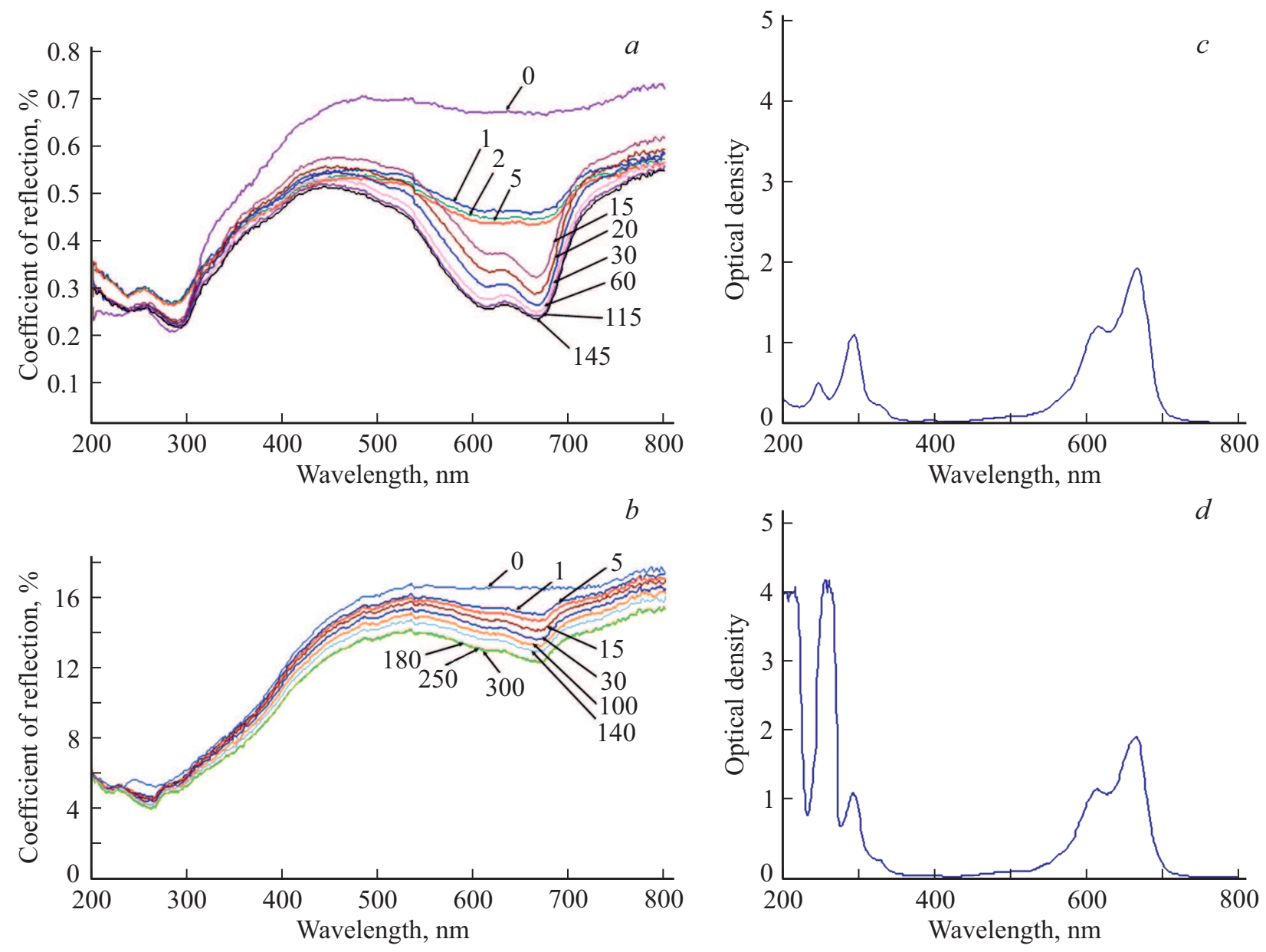

Рис. 3. Спектры, измеренные в различные моменты времени, образца толщиной $0.92 \mathrm{~mm}$ при нормальном атмосферном давлении и температуре $25^{\circ} \mathrm{C}$ : $(a)$ диффузного отражения дентина в процессе диффузии водного раствора МВ $(0.001 \%)$ в течение времени $(\min )$ - цифры на графике; $(b)$ диффузного отражения дентина в процессе диффузии раствора $(0.001 \%)$ MB и CPC $(0.05 \%)$ в течение времени $(\mathrm{min})$ - цифры на графике; $(c)$ спектр поглощения исходного водного раствора МВ $(0.001 \%) ;(d)$ спектр поглощения исходного раствора МВ $(0.001 \%)$ и СРС $(0.05 \%)$.

Основными минеральными компонентами зуба являются гидроксиапатиты, которые присутствуют в зубной ткани в нанокристаллическом состоянии и содержат в структуре большое количество сторонних элементов примесей ( $\mathrm{Na}, \mathrm{Mg}, \mathrm{K}, \mathrm{Fe}, \mathrm{Zn}, \mathrm{Cu}, \mathrm{Ba}, \mathrm{F}, \mathrm{Cl}, \mathrm{C}$, $\mathrm{S})$. Концентрация примесей не превышает $3-5 \%$, но определяет биологические, механические, а в случае эмали и оптические свойства биогенного гидроксиапатита. Вследствие образования примесными элементами в гидроксиапатите ионных комплексов и групп происходит искажение кристаллической решетки, и, как следствие, изменяются физико-химические свойства гидроксиапатита $[28,29]$.

Элементный состав зубов существенно влияет на проницаемость и диффузию веществ в зубной ткани. Установлено, что при проведении деминерализации проницаемость основной массы дентина увеличивается, содержание кальция и фосфора уменьшается, а морфология дентинного слоя изменяется [23]. Элементный состав исследуемых спилов (образцов) зубов человека без деминерализации и при модельной деминерализации в растворе $40 \% \mathrm{HCl}$ в течение $20 \mathrm{~min}$, полученный авторами настоящей работы, представлен в табл. 1.

На продольном срезе (рис. 2, $a, b$ ) дентинные канальца ориентированы в основном перпендикулярно срезу, имея различную форму, угол загиба, плотность и диаметр. Дентинные канальцы имеют вытянутую и изогнутую форму в области коронки зуба, в области корня они проходят прямолинейно, расширяясь веерообразно кверху к наружной поверхности. Между трубочками располагается интертубулярный дентин. Межклеточное вещество дентина представлено коллагеновыми волокнами и основным веществом (содержащим преимущественно протеогликаны), которые связаны с кристаллами гидроксиапатита [28]. Используя SEM-изображения, была определена плотность дентинных канальцев. В исследуемых образцах она составила 20661, 19120, 21125 единиц в $\mathrm{mm}^{2}$.

Раствор МВ в воде $(\mathrm{pH} 7.37 \pm 0.02)$ и в $0.05 \%$ водном растворе СРС $(\mathrm{pH} 7.03 \pm 0.02)$ имеет несколько пиков 
Таблица 1. Элементный состав исследуемых спилов (образцов) зубов человека до деминерализации и после модельной деминерализации

\begin{tabular}{|c|c|c|c|c|c|c|c|c|c|c|c|c|c|}
\hline \multirow{3}{*}{$\begin{array}{c}\text { X-ray } \\
\text { fluorescent } \\
\text { analysis }\end{array}$} & \multicolumn{13}{|c|}{ Element structure before demineralization } \\
\hline & & $\mathrm{S}$ & $\mathrm{Cl}$ & $\mathrm{K}$ & $\mathrm{Sc}$ & $\mathrm{Fe}$ & $\mathrm{Ni}$ & $\mathrm{Cu}$ & $\mathrm{Zn}$ & As & $\mathrm{Rb}$ & $\mathrm{Sr}$ & W \\
\hline & ppm & $3170 \pm 925$ & $332 \pm 125$ & $401 \pm 96$ & $6067 \pm 2500$ & $583 \pm 148$ & $64 \pm 58$ & $20 \pm 8$ & $432 \pm 136$ & $13 \pm 10$ & $817 \pm 250$ & $491 \pm 210$ & $71 \pm 25$ \\
\hline \multirow{2}{*}{ SEM } & Element & \multicolumn{2}{|c|}{$\mathrm{C}$} & \multicolumn{2}{|r|}{$\mathrm{N}$} & \multicolumn{2}{|c|}{$\mathrm{O}$} & \multicolumn{3}{|c|}{$\mathrm{P}$} & \multicolumn{3}{|c|}{$\mathrm{Ca}$} \\
\hline & $\%$ & \multicolumn{2}{|c|}{$51 \pm 12$} & \multicolumn{2}{|c|}{$10 \pm 5$} & \multicolumn{2}{|c|}{$24 \pm 7$} & \multicolumn{3}{|c|}{$5 \pm 2$} & \multicolumn{3}{|c|}{$10 \pm 2$} \\
\hline \multirow{3}{*}{$\begin{array}{c}\text { X-ray } \\
\text { fluorescent } \\
\text { analysis }\end{array}$} & \multicolumn{13}{|c|}{ Element structure after demineralization } \\
\hline & Element & $S$ & $\mathrm{Cl}$ & $\mathrm{K}$ & $\mathrm{Sc}$ & $\mathrm{Fe}$ & $\mathrm{Ni}$ & $\mathrm{Cu}$ & $\mathrm{Zn}$ & As & $\mathrm{Rb}$ & $\mathrm{Sr}$ & $\mathrm{W}$ \\
\hline & $\mathrm{ppm}$ & $2950 \pm 1500$ & $570 \pm 98$ & $485 \pm 126$ & $5103 \pm 2500$ & $426 \pm 58$ & $71 \pm 20$ & $35 \pm 19$ & $230 \pm 85$ & $10 \pm 6$ & $598 \pm 147$ & $412 \pm 256$ & $85 \pm 31$ \\
\hline \multirow{2}{*}{ SEM } & Element & \multicolumn{2}{|l|}{$\mathrm{C}$} & \multicolumn{2}{|r|}{$\mathrm{N}$} & \multicolumn{2}{|c|}{$\mathrm{O}$} & \multicolumn{3}{|c|}{$\mathrm{P}$} & \multicolumn{3}{|c|}{$\mathrm{Ca}$} \\
\hline & $\%$ & \multicolumn{2}{|c|}{$50 \pm 9$} & \multicolumn{2}{|c|}{$11 \pm 4$} & \multicolumn{2}{|c|}{$35 \pm 9$} & \multicolumn{3}{|c|}{$2 \pm 1$} & \multicolumn{3}{|c|}{$2 \pm 1$} \\
\hline
\end{tabular}

поглощения в области спектра 200-800 nm. Основной пик поглощения красителя (в рабочих растворах с концентрацией МB $\left.4.5 \cdot 10^{-5} \mathrm{M}\right)$ имеет два максимума: первый при $668 \mathrm{~nm}$ соответствует мономерной форме красителя, второй, значительно менее выраженный, на длине волны $612 \mathrm{~nm}$ соответствующий димерной форме (рис. 3, $c, d$ ). В ультрафиолетовой области спектра МС (MB) имеет два значительно меньших пика поглощения с максимумами на длинах волн 246 и $295 \mathrm{~nm}$ (в водном растворе МВ) (рис. $3, c$ ). МВ в $0.05 \%$ водном растворе СРС имеет дополнительные ярко выраженные пики поглощения при 215 и $250 \mathrm{~nm}$, характерные для раствора СРС (рис. 3,d). Проникая в дентин зуба, МВ изменяет форму спектров отражения образцов дентина, что проявляется в виде характерных полос поглощения МВ на спектре диффузного отражения дентина (рис. $3, a, b)$. Из представленных рисунков хорошо видно, что все изменения в спектрах отражения локализованы в спектральной области 580-700 nm, соответствующей полосам поглощения димерной и мономерной форм водного раствора МВ. В области длин волн 750-800 nm происходит снижение диффузного отражения на 23-25\% (рис. $3, a, b$ ), что говорит о некотором уменьшении коэффициента рассеяния при иммерсии образца дентина в растворе МВ. В области 500-750 nm, соответствующей полосам поглощения димерной и мономерной форм красителя, отчетливо видно значительное снижение отражения. В течение первого часа диффузии красителя коэффициент диффузного отражения меняется быстро (рис. $3, a, b$ ), а затем происходит насыщение временной зависимости, что говорит о насыщении среза дентина красителем по всему объему. При этом положения пиков поглощения молекул мономеров и димеров МВ не смещаются и остаются вблизи длин волн 612 и $668 \mathrm{~nm}$, так же как в водном растворе и в растворе с СРС.

Для образца среза дентина, SDR которого представлены на рис. 3, $a$, насыщение произошло через $100 \mathrm{~min}$ нахождения в водном растворе МВ. При нахождении того же спила (образца) дентина в МВ, растворенном в $0.05 \%$ водном растворе СРС с концентрацией МВ $(0.001 \%)$ (рис. $3, b)$, насыщение произошло только к моменту времени $200 \mathrm{~min}$ и в меньшей степени.

На рис. 4, $a, b$ показаны типичные кинетические кривые для изменения $\Delta A$ образца зуба при его окраске МВ на длине волны $668 \mathrm{~nm}$. Хорошо видно, что изменения оптической плотности образца зуба, находящегося в контакте с водным раствором МВ, наблюдаются в течение примерно $100 \mathrm{~min}$ с момента его взаимодействия с раствором MB, после чего диффузия красителя в образце прекращается, и изменения оптической плотности не наблюдаются. Изменения оптической плотности образца зуба, находящегося в контакте с раствором (0.001\%) MB в $0.05 \%$ СРС, наблюдаются в течение примерно $200 \mathrm{~min}$.

Коэффициенты диффузии $D$ MB в разных средах рассчитывали по уравнению (2), учитывая коэффициенты, полученные после аппроксимации экспериментальных данных методом наименьших квадратов. Вычисления для каждого образца выполнялись для десяти длин волн в спектральной области 600-700 nm, соответствующей максимумам пиков поглощения димерной $(612 \mathrm{~nm})$ и мономерной $(668 \mathrm{~nm})$ форм красителя, а полученные значения усреднялись. Результаты расчета коэффициента диффузии для всех образцов представлены в табл. 2. В среднем он составляет для водного раствора $0.001 \% \mathrm{MB}(6.74 \pm 1.32) \cdot 10^{-6} \mathrm{~cm}^{2} / \mathrm{s}$, а для $0.001 \% \mathrm{MB}$ в мицеллярном расторе СРС $(1.93 \pm 0.24) \cdot 10^{-6} \mathrm{~cm}^{2} / \mathrm{s}$.

Полученные значения коэффициентов диффузии находятся в диапазоне $10^{-5}-10^{-6} \mathrm{~cm}^{2} / \mathrm{s}$, что характерно для водных растворов красителей в тканях $[18,30]$. Так, значение коэффициента диффузии согласуется с данными, представленными в работе [31], где коэффициент диффузии в дентине составил $2.7 \cdot 10^{-6} \mathrm{~cm}^{2} / \mathrm{s}$ в случае диффузии воды и $0.19 \cdot 10^{-6} \mathrm{~cm}^{2} / \mathrm{s}$ в случае диффузии 

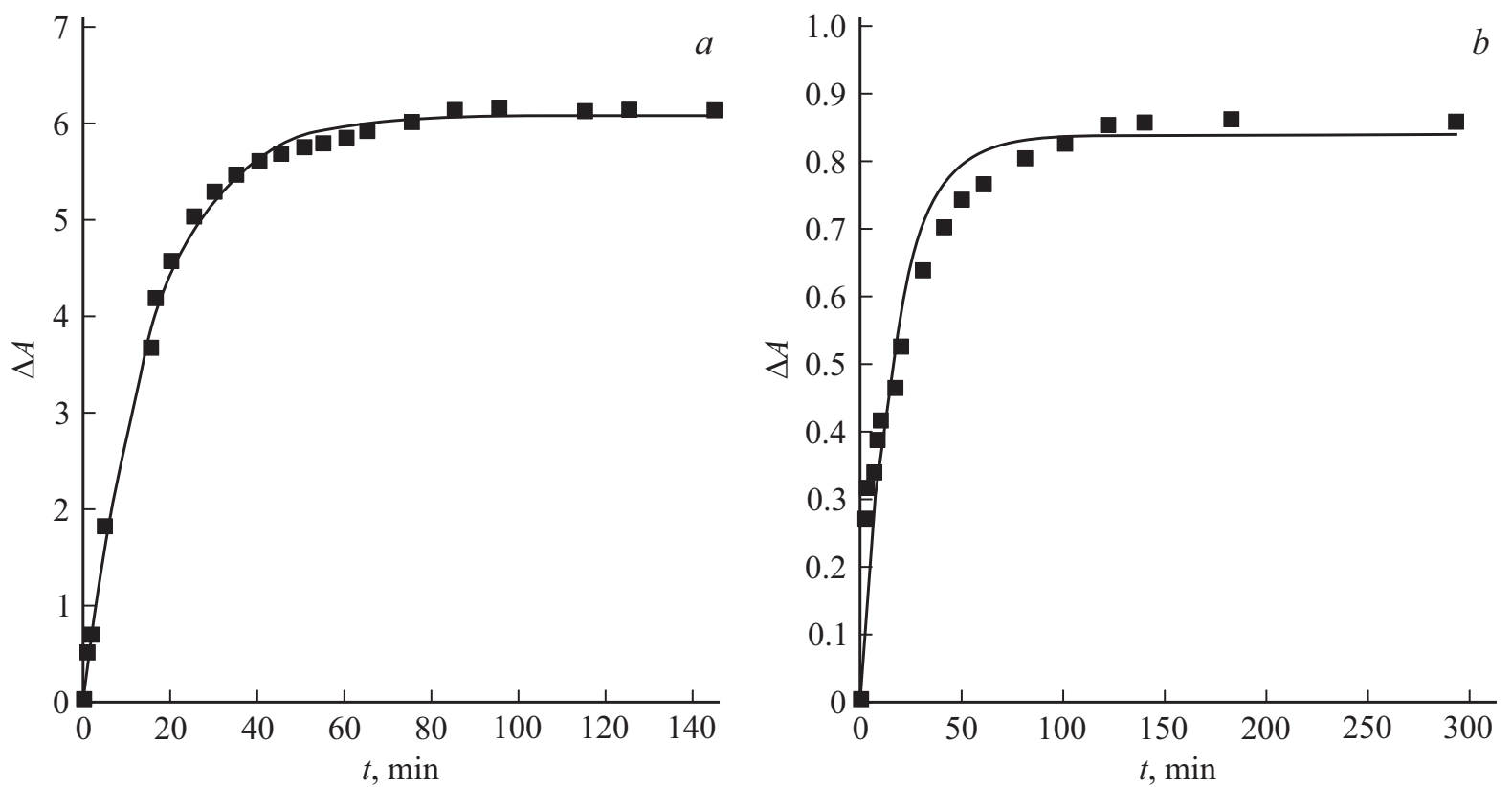

Рис. 4. Кинетика разностной эффективной оптической плотности образца дентина при его взаимодействии с: (a) водным раствором MB $(0.001 \%),(b)$ раствором MB $(0.001 \%)$ в 0.05\% СРС. Символы соответствуют экспериментальным данным, сплошная кривая представляет аппроксимацию экспериментальных данных в рамках предложенной модели свободной диффузии.

Таблица 2. Параметры спила зуба человека и коэффициенты диффузии растворов МС (МВ) (0.001\%)

\begin{tabular}{|c|c|c|c|c|}
\hline \multirow{2}{*}{\multicolumn{2}{|c|}{ Parameter }} & \multicolumn{3}{|c|}{ №slice } \\
\hline & & 1 & 2 & 3 \\
\hline \multicolumn{2}{|c|}{ Slice thickness, mm } & 0.92 & 0.97 & 0.93 \\
\hline \multicolumn{2}{|c|}{ Average diameter of dentinal tubules, $\mu \mathrm{m}$} & $2.94 \pm 0.81$ & $2.32 \pm 1.07$ & $3.08 \pm 0.94$ \\
\hline \multicolumn{2}{|c|}{ Density of number of dentinal tubules, $1 / \mathrm{mm}^{2}$} & 20661 & 19120 & 21125 \\
\hline \multirow{2}{*}{ Saturation time, $\min$} & MB in water & 100 & 120 & 60 \\
\hline & $\mathrm{MB}$ in $0.05 \% \mathrm{CPC}$ & 200 & 185 & 210 \\
\hline \multirow{2}{*}{$\begin{array}{c}\text { Diffusion coefficient } \\
\text { of } \mathrm{MB} \text { in solutions, } \mathrm{cm}^{2} / \mathrm{s}\end{array}$} & $\mathrm{MB}$ in water & $(6.74 \pm 1.32) \cdot 10^{-6}$ & $(5.42 \pm 1.08) \cdot 10^{-6}$ & $(8.06 \pm 1.20) \cdot 10^{-6}$ \\
\hline & $\mathrm{MB}$ in $0.05 \% \mathrm{CPC}$ & $(1.93 \pm 0.24) \cdot 10^{-6}$ & $(1.69 \pm 0.18) \cdot 10^{-6}$ & $(2.17 \pm 0.22) \cdot 10^{-6}$ \\
\hline
\end{tabular}

$44 \%$ водного раствора глицерина. Коэффициент диффузии МВ в воде равен $0.38 \cdot 10^{-5} \mathrm{~cm}^{2} / \mathrm{s}$ [32].

МВ относится к классу основных растворителей. В водном растворе под действием полярных молекул воды существует равновесие между двумя формами красителя: положительно заряженной (более гидрофильной) и незаряженной формой MB (более гидрофобной). Это равновесие нарушается в мицеллярных водных раствоpax ПАВ (surfactant). Характер смещения этого равновесия определяется зарядом мицеллы ПАВ (surfactant). При концентрациях, равных или больше ССМ, ПАВ (surfactant) образуют мицеллы. СРС является катионным ПАВ (surfactant). Благодаря сильному электростатическому притяжению значительное число противоионов (до $80 \%$ и более) связаны с поверхностью мицеллы и составляют с ней единое целое [33]. Положительно заряженной форме МВ в результате электростатического отталкивания одноименных зарядов практически невозможно проникнуть к ядру мицеллы СРС, в то время как гидрофобная компонента МВ может легко достичь ядра мицеллы, поскольку она не заряжена. Происходит процесс солюбилизации гидрофобной формы МВ в ядре мицеллы СРС, приводящая к перестройке мицеллярного раствора и укрупнению мицелл. Увеличивается также среднее количество молекул в мицелле, происходит агрегация. Этим объясняется меньшее проникновение МВ в растворе $0.05 \%$ СРС по сравнению с водным раствором красителя. МВ способен взаимодействовать с самим собой в водном растворителе с образованием комплексных ассоциатов, которые плотным слоем 

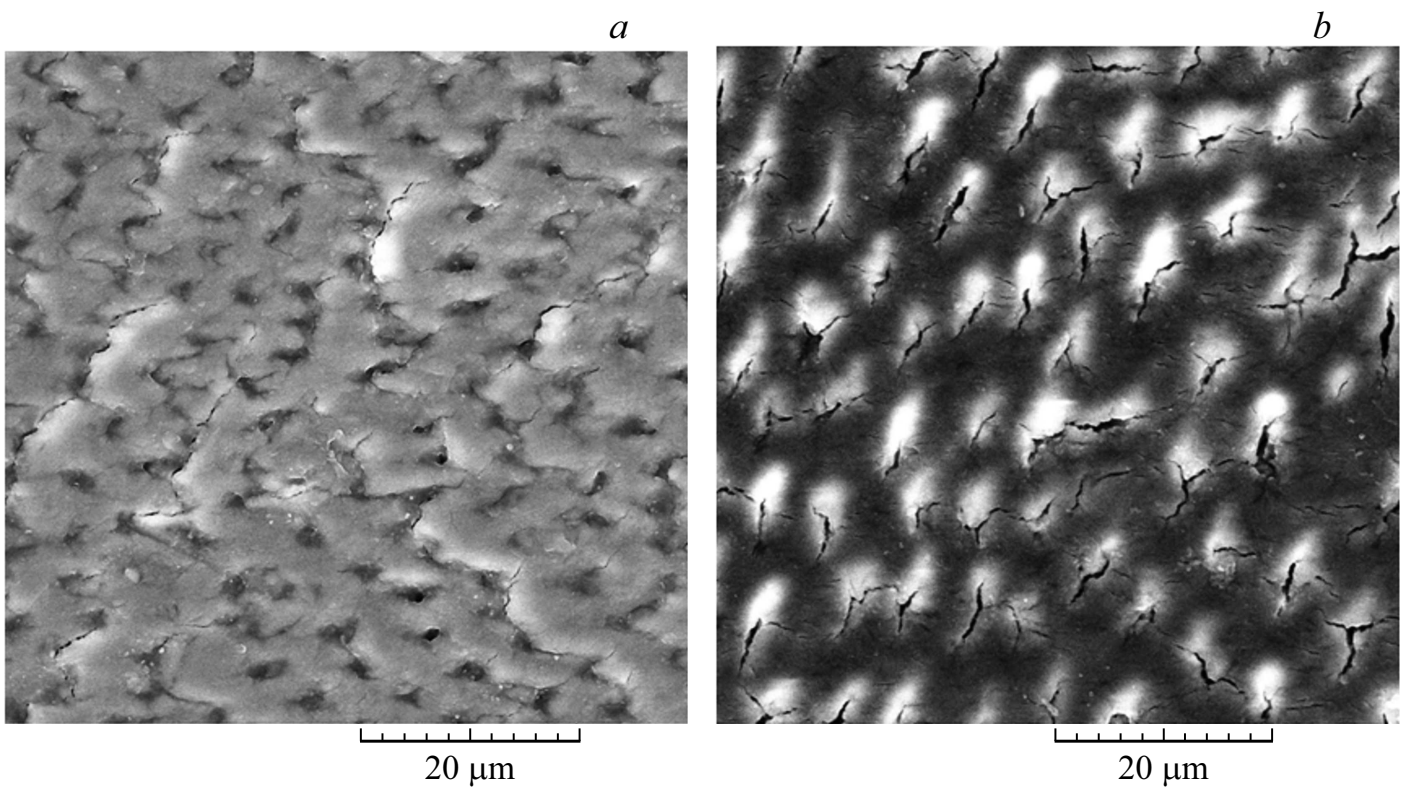

Рис. 5. Электронные микрофотографии (SEM) продольного спила (образца) дентина зуба человека в средней части коронки (при увеличении в 10000 раз) после диффузии: (a) водного раствора $0.001 \%$ МВ после прокраски спила в течение 100 тіп; (b) мицеллярного раствора $0.001 \%$ МВ после прокраски спила в течение $200 \mathrm{~min}$.

покрывают поверхность образца, застилают входы в дентинные канальцы и удерживаются на поверхности дентина за счет водородных связей (рис. 5, a). СРС в концентрации, превышающей мицеллообразование, также покрывает плотным слоем поверхность дентина, образуя мицеллярную пленку, закрывающую входы в дентинные канальцы (рис. 5, $b$ ).

\section{Микробиологические исследования}

При количественной обработке результатов микробиологических исследований проводили подсчет показателя KOE (CFU), который отражает число выживших бактериальных колоний. Считается, что каждая колония соответствует выжившей бактериальной клетке (рис. 6). Все варианты опыта культивировали в одинаковых условиях. Контролем служили посевы, культивированные в физиологическом растворе. Сравнение проводили между числом CFU в контролях и числом CFU при воздействии раствора $0.001 \%$ МВ в воде, $0.001 \%$ МВ в мицеллярном растворе СРС, лазерного излучения $(662 \pm 0.2 \mathrm{~nm})$, а также комбинированного воздействия лазерного излучения с вышеназванными растворами МВ. Статистическую обработку результатов проводили, рассчитывая среднее арифметическое количество клеток $(M)$ в $1 \mathrm{ml}$ и стандартное отклонение $(m)$ с последующим определением достоверности различий с контрольными высевами между средними величинами с вероятностью 95\%.

Стафилококк (в частности, золотистый) является условно патогенной бактерией, распространенным и довольно опасным возбудителем острых и хронических заболеваний слизистой пародонта человека независимо

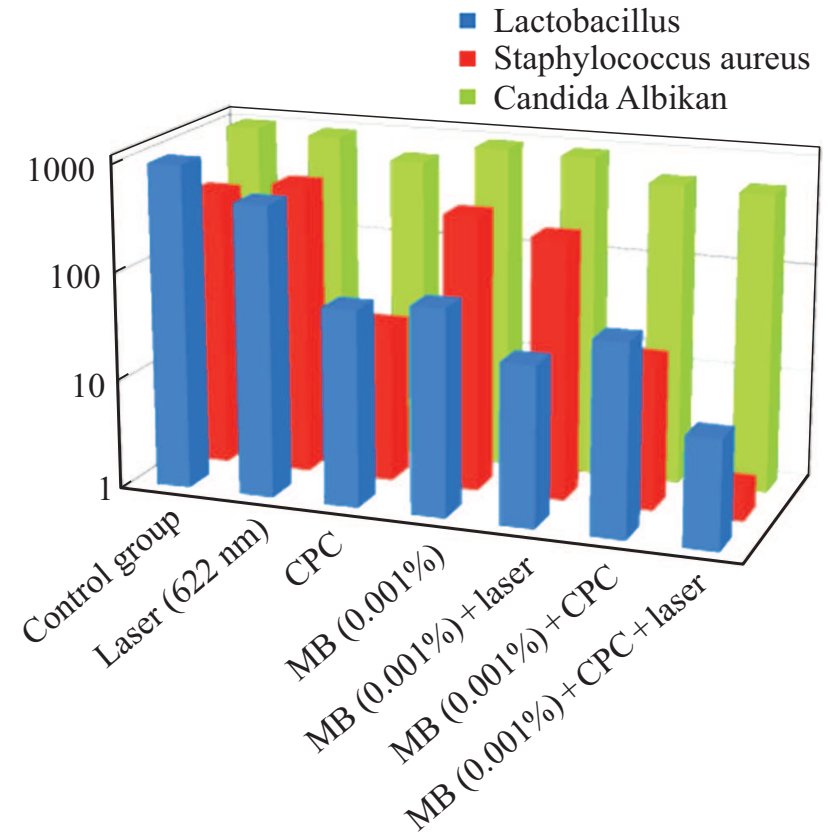

Pис. 6. Число CFU после воздействия: раствора $0.001 \%$ MB в воде, $0.001 \% \mathrm{MB}$ в мицеллярном растворе СРС, лазерного излучения $(662 \pm 0.2 \mathrm{~nm})$, раствора $0.001 \% \mathrm{MB}$ в воде совместно с лазерным излучением $(662 \pm 0.2 \mathrm{~nm}), 0.001 \%$ МВ в мицеллярном растворе СРС совместно с лазерным излучением $(662 \pm 0.2 \mathrm{~nm})$, а также в контроле.

от возраста. Лактобактерии выступают одними из основных природных антагонистов кандид и входят в состав нормальной микрофлоры ротовой полости человека. Однако при определенных неблагоприятных факторах 
равновесие может сдвигаться, и кандиды могут вызывать поражение слизистой полости рта, так называемые кандидозы с вовлечением в патологический процесс других тканей. При воздействии $0.001 \%$ МВ водного и в растворе СРС без облучения на лактобактерии число $\mathrm{CFU} / \mathrm{ml}$ снизилось на 92 и 94\% соответственно. Применение комбинированного действия лазера и МВ в водном растворе и растворе СРС в течение $10 \mathrm{~min}$ показало уменьшение числа $\mathrm{CFU} / \mathrm{ml}$ на 97 и 99\% соответственно. Воздействие $0.001 \%$ МВ водного и в растворе CPC на Candida albicans способствовало уменьшению числа CFU/ml соответственно на 7 и 42\%. Применение комбинированного действия лазера и $\mathrm{MB}$ в водном растворе и растворе СРС в течение $10 \mathrm{~min}$ показало уменьшение числа $\mathrm{CFU} / \mathrm{ml}$ на 11 и 45\% соответственно. При воздействии $0.001 \%$ МВ водного и в растворе СРС без облучения на Staphylococcus aureus число CFU/ml снизилось на 5 и 93\%. Применение комбинированного действия лазера и $\mathrm{MB}$ в водном растворе и растворе CPC показало уменьшение числа CFU/ml на 31 и 99\%.

\section{Выводы}

C помощью спектроскопии диффузного отражения определен коэффициент диффузии МВ в сильно рассеивающей среде, а именно в дентине зуба человека, который составил в среднем в водном растворе $0.001 \% \mathrm{MB}$ $(6.74 \pm 1.32) \cdot 10^{-6} \mathrm{~cm}^{2} / \mathrm{s}$ и $(1.93 \pm 0.24) \cdot 10^{-6} \mathrm{~cm}^{2} / \mathrm{s}$ в мицеллярном растворе. Результаты получены в рамках модели свободной диффузии. При фотодинамическом воздействии лазерного излучения на все исследуемые штаммы при их сенсибилизации растворами МВ показан выраженный ингибирующий эффект. При этом было продемонстрировано, что мицеллярная среда СРС увеличивает антибактериальный эффект и не подавляет способность МВ к фотоактивации.

\section{Финансирование работы}

Работа выполнена при финансовой поддержке Российского фонда фундаментальных исследований 17-00$00272(17-00-00275(\mathrm{~K}))$.

\section{Соблюдение этических стандартов}

Настоящая статья не содержит каких-либо исследований с участием людей в качестве объектов исследований.

\section{Конфликт интересов}

Авторы заявляют, что у них нет конфликта интересов.

\section{Список литературы}

[1] Kishen A., Vedantam S. // Dental Materials. 2007. V. 23. N 10. P. 1296.

[2] Genina E.A., Bashkatov A.N., Tuchin V.V. // Advances in Optical Technology. 2008. P. 267867.

[3] Tuchin V.V., Xu X., Wang R.K. // Appl. Opt. 2002. V. 41. P. 258.

[4] Tuchin V.V. Tissue Optics: Light Scattering Methods and Instruments for Medical Diagnostics. Bellingham: SPIE Press, 2015.

[5] Hanks C.T., Fat J.C., Wataha J.C., Corcoran J.F. // J. Dent. Res. 1993. V. 72. N 5. P. 931.

[6] Zhang Xu, Koon Gee Neoh, Anil Kishen // J. Dentistry. 2008. V. 36. P. 1005.

[7] George S., Kishen A. // J. Endodontics. 2007. V. 33. P. 1421.

[8] Sum C.P., Mohanty S., Gupta P.K., Kishen A. // J. Biomed. Opt. 2008. V. 13. N 4. 044017. doi 10.1117/1.2957972

[9] Kishen A., Sum C.P., Mathew S., Lim C.T. // J. Endodontics. 2008. V. 34. N 7. P. 850. doi 10.1016/j.joen.2008.04.006

[10] Carvalho E.S., Mello I., Albergaria S.J., Habitante S.M., Lage-Marquez J.S., Raldi D.P. // Photomedicine and Laser Surgery. 2011. V. 29. N 8. P. 559.

[11] Altshuler G., Tuchin V.V. U.S. Patent № 7354448, 2008.

[12] Aghahosseini F., Arbabi-Kalati F., Fashtami L.A., Djavid G.E., Fateh M., Beitollahi J.M. // Lasers Surg. Med. 2006. V. 38. P. 33.

[13] George S., Kishen A. // J. Biomed. Opt. 2007. V. 12. N 3. P. 034029.

[14] Titorenko V.A. Antimicrobial Action of Helium-Neon Laser Irradiation on Periodontal Pocket Microflora Sensitized by Methylene Blue. Ph.D. Thesis. Saratov, 2002.

[15] Usacheva M.N., Teichert M.C., Biel M.A. // Lasers Surg. Med. 2001. V. 29. N 2. P. 165.

[16] Genina E.A., Bashkatov A.N., Chikina E.E., Knyazev A.B., Mareev O.V., Tuchin V.V. // Laser Physics. 2006. V. 16. N 7. P. 1128.

[17] Genina E.A., Titorenko V.A., Simonenko G.V., Bashkatov A.N., Shub G.M., Lepilin A.B., Tuchin V., Yaroslavsky I.V., Altshuler G.B. // J. Innovative Opt. Health Sci. 2011. V. 4. N 4. P. 437.

[18] Котык А., Яначек К. Мембранный транспорт. М.: Мир, 1980. $344 \mathrm{c}$.

[19] Trunina N., Derbov V., Tuchin V., Altshuler G. // Proc. SPIE. 2007. V. 6791. P. 67910T.

[20] Трунина Н.А. // Опт. и спектр. 2010. Т. 109. № 2. С. 190.

[21] Bashkatov A.N., Genina E.A., Tuchin V.V., Chikina E.E., Knyazev A.B., Mareev O.V. // Proc. SPIE. 2005. V. 5863. P. 178.

[22] Генина Э.А., Башкатов А.Н., Чикина Е.А., Тучин В.В. // Биофизика. 2007. Т. 52. № 6. Р. 1104.

[23] Mjör I.A., Nordahl I. // Arch. Oral. Biol. 1996. V. 41. P. 401.

[24] Kienle A., Michels R., Hibst R. // J. Dental Research. 2006. V. 85. N 10. P. 955.

[25] Грисимов В., Радлинский С. // ДентАрт. 2006. Т. 1. № 3. C. 26.

[26] Lima R.R., Araujo L.M., Affonso P.R., Maranhão K.M., Lamarão S.S. // Ciencia Animal Brasileira. 2009. V. 10. N 4. P. 1328 
[27] Seredin P.V., Kashkarov V.M., Lukin A.N., Goloshchapov D.L., Al-Zubaidi A.A., Ippolitov Yu.A., Julian R., Doyle S. // Конденсированные среды и межфазные границы. 2013. T. 15. № 3. C. 224.

[28] Xia W., Lindahl C., Persson C., Thomsen P., Lausmaa J., Engqvist H. // J. Biomaterials and Nanobiotechnology. 2010. V. 1. I. 1. P. 7.

[29] Kinney J.H., Oliveira J., Haupt D.L., Marshall G.W., Marshall S.J. // J. Mater. Sci. Mater. Med. 2001. V. 12. P. 743.

[30] Селибонов А.А., Тучин В.В. // Биофизика. 2018. Т. 63. № 6. C. 1211.

[31] Trunina N.A., Lychagov V.V., Tuchin V.V. // Proc. SPIE. 2010. V. 7563 OU.

[32] Derek G.L. // J. Chem. 1988. V. 66. P. 2452.

[33] Чернова Р.К., Доронин С.Ю. Определение органических аналитов в растворах ПАВ: ионные и мицеллярные эффекты. Саратов: изд-во Сарат. ун-та, 2017. С. 200. 